\title{
The Effect of Simulation-Based Training on Nursing Students' Communication Skill, Self-Efficacy and Clinical Competence for Nursing Practice
}

\author{
Salwa A. Mohamed ${ }^{1,2}$, Imad H. Fashafsheh ${ }^{3,4^{*}}$ \\ ${ }^{1}$ Medical Surgical Nursing, Faculty of Nursing, Fayoum University, Fayoum, Egypt \\ ${ }^{2}$ Medical Surgical Nursing, University of Bisha, Bisha, Saudi Arabia \\ ${ }^{3}$ Critical Care Nursing, University of Bisha, Bisha, Saudi Arabia \\ ${ }^{4}$ Nursing College, Arab American University, Jenin, Palestine \\ Email: ^fashafsheh@gmail.com
}

How to cite this paper: Mohamed, S.A. and Fashafsheh, I.H. (2019) The Effect of Simulation-Based Training on Nursing Students' Communication Skill, Self-Efficacy and Clinical Competence for Nursing Practice. Open Journal of Nursing, 9, 855-869. https://doi.org/10.4236/ojn.2019.98064

Received: July 12, 2019

Accepted: August 19, 2019

Published: August 22, 2019

Copyright () 2019 by author(s) and Scientific Research Publishing Inc. This work is licensed under the Creative Commons Attribution International License (CC BY 4.0).

http://creativecommons.org/licenses/by/4.0/

(c) (i) Open Access

\begin{abstract}
Background: Simulation-based training is a new strategy in teaching that gives the students good opportunities to learn and apply what they learn in nursing care safely. Aim: This study conducted to evaluate the effects of simulation-based training on nursing students' communication skill, self-efficacy and clinical competence in practice. Subjects and Methods: Quiz-experimental design was used in this study (pre-posttest intervention), it was carried out on 100 nursing students first semester in 2019 using low and high-fidelity simulators. This study was carried out at College of Applied Medical Sciences-Bshia University. Data Collection: demographic data, communication skill, selfefficacy and clinical competence questionnaires. Analysis is done by SPSS version 20 software. Results: Participants who received the simulation-based training, showed statistical significant improvement in communication skill, self-efficacy, and clinical competence scores after participation in the simulation program $(\mathrm{t}=-32.64, \mathrm{p}=0.001 ; \mathrm{t}=-19.9, \mathrm{p}=0.001 ; 16.4, \mathrm{p}=0.001)$. Also, there are significant relation between gender and clinical competency $(\mathrm{t}=$ $2.768, \mathrm{p}<0.05)$. Conclusion: Simulation-based training in medical courses is effective in enhancing communication skill, self-efficacy and clinical competence. Multiple-patient simulations as a teaching-learning strategy in the nursing curriculum are highly recommended.
\end{abstract}

\section{Keywords}

Simulation-Based, Nursing Students, Communication Skill, Self-Efficacy, Clinical Competence 


\section{Introduction}

Nurse educators use many activities in clinical simulation as patient simulators for transiting student to professional nurse through more opportunities to patient care [1]. It was first implemented in selecting nursing curriculums in 1960's [2]. The simulation aims to provide students with the artificial replication of the real world situation to be knowledgeable, skillful and critically thinkers by applying complex scenarios in a safe environment. Learning on hospital patients only limits students in developing their analytical skills to problem-solving during emergency and crisis situation [3].

Multimedia sources, anatomical models, and simulators of the human body form the core of simulation-based learning. Simulation is one of the strategies that nurse educators can use to deal with situations in the clinical area, which cause stress and anxiety among student nurses as well as situations such as a fear of making mistakes, negative responses to the suffering and death of patients [4]. Oermann \& Gaberson [5] also note that students develop psychomotor and technological skills to improve the students' critical thinking skills through clinical situations and make independent decisions.

Nursing educators facilitate learning of theoretical and practical clinical skills among student nurses, and help students to combine theory and practice at all levels by applying appropriate teaching approaches and simple techniques. The clinical area is ideally the primary place of learning practical skills for student nurses. However, the competition for learning opportunities between nursing students and allied health and medical students restricts nursing students learning activity that leads to sub-optimal experiences for content integration and mastery. The increasing number of student nurse intake restricts student nurses learning activities, thus increasing the importance of incorporating simulation into the nursing curriculum as an alternative to clinical placements and for replacing clinical hours [6] [7].

Effective communication is the stone base with patient interactions and intervention that essential to achieve desired patient outcomes. Therapeutic communication skills are significantly confirmed in the core curriculum [8]. Tosterud et al. [9] suggest that "Simulation as a way to learn communication skills at basic level nursing and learn the students to be effectively lead conservation in a safe, virtual, simulated clinical environment". However, communication skill is sole of several topics in the development of nurses' clinical competence [10]. The survey done by Gantt [11] in which he uses the Clark simulation evaluation rubric from two different nursing colleges, evaluated area were assessment, history gathering, critical thinking, communication, patient teaching, and to recognize necessary diagnostic studies. In psychomotor domain simulation-based nursing as educational intervention was highly effective. Kim et al. [12] also evidence the impact of simulation-based education when not relative to fidelity level, so it is important to use a proper level of simulation to meet all the educational goals and outcomes. Self-efficacy is defined as individuals beliefs to attain 
capable for learning and performing actions at designated levels of performance [13].

In education, self-efficacy is associated with student success by positively academic performance achievement, predictor of students' motivation, and self-regulatory outcomes [14] [15]. Valizadeh et al. [16] reported that improvement of self-efficacy among undergraduate nursing students after applying simulation to learn peripheral venous catheterization in children. Other studies [17] [18] [19] also reported that simulation-based training has a positive impact on improving self-efficacy in nursing students after participating in simulation scenarios.

Competence is the ability to perform a task with desirable outcomes [20]. Kane [21] added the competency can grow through individual experience and integrate the knowledge, skills and judgment in order to perform effectively in the domain of learning for safe and ethical nursing practice

Competence-based learning (CBL) uses creative methods of teaching in the nursing degree are increased and it focuses on what students learn and not on the time spent in the classroom [22]. One of the main methods used for improving the development of competence in nursing education is clinical simulation [23]. Therefore, the purpose of the present study was to evaluate the effect of simulation-based training on nursing students' communication skill, self-efficacy and clinical competence for nursing.

\subsection{Significance of the Study}

Simulation can be used as a helpful learning tool and cannot replace patient interaction [24]. Little literature found in the past few years for evaluation simulation as a method of education, and also very little research's studied the correlation of student and faculty perceptions regarding simulation-based education [25].

Simulation labs in the department of nursing in applied medical college University of Bisha were started within the program, and more than eight patches graduated as staff nurses, no studies are done to evaluate the progress, methods of evaluation and the effect on nursing students competences. The aim of this pre-post study is to measure changes happen to our student who finishes most simulation needed courses in communication, self-efficacy and competences.

\subsection{Operational Definitions}

Simulation-Based Training: It is relevant to the care of patients with medical and critical nursing program for third and fourth year nursing students.

Self-Efficacy: "Refers to an individual's belief in his or her ability to succeed in specific situations or accomplish a task to produce specific performance attainments" [13] [26].

Competence: "Refers to ability of the student to integrate the skills, knowledge and attitudes during in clinical practice". 


\subsection{Aim of This Study}

To evaluate the effect of simulation-based training on nursing students' communication skill, self-efficacy and clinical competence for nursing.

\subsection{Research Hypothesis}

H1: Students communication skill score will be different in pretest from posttest between study group whom participated in the simulation-based training course required of nursing practice.

$\mathrm{H} 2$ : There will be a difference in self-efficacy between the study group pretest and posttest whom participated in simulation-based training course required of nursing practice.

H3: There will be a difference in clinical competence between the study group pretest and posttest whom participated in the simulation-based training in course required of nursing practice.

\section{Subjects and Methods}

\subsection{Study Design}

Quasi-experimental one-group pretest-posttest was used for this study.

\subsection{Study Setting}

This study was conducted at nursing department-College of Applied Medical Sciences, medical surgical and critical simulation labs in University of Bisha, Saudi Arabia. The medical labs contain moderate-fidelity medical and critical simulators.

\subsection{Sample}

A convenience sample of 100 junior students from third and fourth years' undergraduate nursing students.

\subsubsection{Inclusion Criteria}

Students enrolled in a medical surgical nursing and critical care nursing course participated in the study. Participants' Students must be enrolled in the basic and advance adult health care and critical care courses of the undergraduate nursing program, over the age of 19 and willing to participate in the study.

\subsubsection{Exclusion Criteria}

Students did not receive any training in all simulators related to program requirement prior to participating in this study.

\subsubsection{Variables}

Dependent variables: Communication skill (CS) score and self-efficacy (SES) score and clinical competence (CC) score.

Independent variables: Demographic characteristics of students and previous experience with simulators. 


\subsection{Instruments}

Data were collected by four tools: 1) Demographic data; 2) Communication skill (CS); 3) General self-efficacy Scale (GSES); and Clinical Competence Scale (CCS).

Tool I: Demographic data: This tool developed by investigator, it includes gender, age, semester work, and previous experience with simulation related course program.

Tool II: Communication skill: It was adopted from Yoo [27], and adapted by researchers to evaluate nursing students' ability to communicate. It consists of ten questions with a 3-point LikertScale: (5) questions to locate professional attitude of the nursing students and (5) questions to determine the sufficiency of explanation given during nursing care. Scale score range from 10 to 30, high score mean high communication skill.

Tool III: Students Self Efficacy (SSE): This tool adopted by Yang and Park [28]. To assess perception about the ability to cope with a variety of different situations in life. SSE consisted of 14 items with a 5-point scale, each response starts from 1 (strongly disagree) to 5 strongly agree. Scale score range from 14 to 60 , with 60 indicated, the higher the level of clinical cope. The average time to complete the tool is 4 - 5 minutes.

Tool IV: Clinical Competence (CC): Adopted from Freeth and Fry [29], it is used to assess perception of nursing students about teaching and learning in clinical skill center. It consists of 24 questions: Five about the nursing process skills, five for determining the ability of the students to perform direct nursing interventions, four for psychosocial nursing ability, four to determine ability of patient education, three to assess nursing student's performance ability, and three questions monitoring capabilities in physical examination of the patients. The responses to all questions were on 5-point LikertScale, from (1) strongly agree to (5) strongly disagree, the maximum score of 120 and minimum were 24 . The average time to complete the tool is $15-20$ minutes. It revealed the highlighting the students were positive about learning with the clinical skill centers.

\subsection{Validity and Reliability of the Tools}

Face and content validity done for the tools by five expertise in the field of nursing and medical education, and necessary modifications done. The reliability of the tool $(2,3$, and 4$)$ was tested using the internal consistency method. It proved to be high with Cronbach's alpha reliability coefficients was $0.92,0.88$, and 0.90 .

\subsection{Pilot Study}

A pilot study was conducted on ten students to check and make sure the clarity, applicability to identify any difficulties with their application, and to determine the time needed for completion of the tools.

\subsection{Ethical Considerations}

Verbal and written information about the purpose of the study and the proce- 
dure was given for students who agree to participate voluntarily, students notified of their right to withdraw at any time without explanation. Strict confidentiality of the information provided to the researcher is assured.

\subsection{Procedures}

- Approval for the study was taken; the researcher based on previous literature developed tools.

- The tools were tested for validity and reliability by 5 experts from medical and nursing staff, the necessary modifications were done.

- A pilot study was done on 10 nursing students to test clarity and applicability of the tool, and time needed to conduct the study.

- Data collection carried out in the period January 2019 until April 2019.

- The methods of teaching used in the simulation-based medical education program were short lectures, video, group discussions, demonstration and re-demonstration of low and moderate fidelity simulation.

- Participants were not randomly selected and all attended simulation-based training program. The scenarios consisted of situations, that nursing student might handle like ECG, blood transfusion, intravenous injections, providing oxygen therapy, wound and stoma care, Ryle insertion and removing.

- Simulation training was conducted in the simulation lab between four to five students over a period of 16 hours/week for 3 weeks for completing simulation. However, one week before the started simulation-based learning session to prerequisite course and responsibility of each student before adult health care clinical practice started, four sessions were conducted of a total of 64 hours.

- In the first section, pre-briefing orientation was conducted, about session aims, learning outcomes and structure and delivery scenarios were presented. Explanation of nature process and allow discussion for more clarify. Then, the researchers allow students to attend nearly 10 minute's video session about the parts to explain in simulations.

- In the 2nd and 4th sessions, simulations based medical education was conducted, in which sessions included simulation explanation, clear steps of procedure and re-demonstration. After sessions (debriefing) students were allowed to give feedback by explaining the strengths and weaknesses of the simulation situations.

- Data collections through demographic data, communication skill, self-efficacy and clinical competence were assessed for all students pre-posttest after receiving the intervention, to check out the effect of simulation program effect on communication skill, students self-efficacy and clinical competence. The time for all tools collecting within $30-40$ minutes. In addition, the total times needed for monitoring the activities through courses within 45 hours.

\subsection{Data Analysis}

All data were entered into a database and statistical data analysis was con- 
ducted using the Statistical Package for Social Science (SPSS) software. A p-value of 0.05 was considered as statistically significant. Descriptive statistics, including frequencies, percentages, means, and standard deviation was used to describe the data. Paired t test was used to assess the differences between pre and post HFS according to communication skills, self-efficacy, and competency. An independent $t$ test and ANOVA were used to make comparison between demographic characteristics and communication, self-efficacy, and competency.

\section{Results}

\subsection{Descriptive Characteristics}

Table 1 shows that about half (49\%) of the nursing students age between 20 to 24 years. As regards study level, more than half (53\%) of them were level 6 . The majority of the students (66\%) had no previous experience in simulation.

\subsection{Impact of Patient Simulation (PS) on Communication Skill}

Using the paired t-test analysis for sample (see Table 2) revealed a significant statistical difference between the pre and post HFS intervention $(\mathrm{t}=-32.64, \mathrm{p}<$ 0.001). Item analysis showed also that item means scores for the post HSF intervention between $2.57(\mathrm{SD}=0.50)$ for item 3 (Student explains to the patient what is doing and why) and $2.73(\mathrm{SD}=0.45)$ for item 7 (Student explains to the patient that the action could be painful).

Table 3 described the comparsion between pre and post-intervention group related to self-efficacy after implementing simulation program. It reveals that a significant statistical difference regarding pre and post-intervention $(t=-19.9, p$ $<0.001)$. Also, improved means scores for the post-intervention ranged from item 2 to item 7 (2.72 and 4.3 respectively).

\subsection{Impact of Simulation-Based Training on Clinical Competence}

Table 4 reports that improved mean scores clinical competence posttest simulation intervention compared with pretest simulation $(\mathrm{t}=-16.4, \mathrm{p}<0.001)$.

\subsection{Demographic Characteristics and Communication, Self-Efficacy, and Clinical Competency}

Table 5 showed that a significant relation between gender and clinical competency $(\mathrm{t}=2.768, \mathrm{p}<0.05)$. While no significant relation between communication skill, self-efficacy, clinical competence and the study level, previous experience of simulation $(\mathrm{p}>0.05)$.

\section{Discussion}

The aim of this study was to evaluate the effect of using simulation-based training on nursing students' communication skill, self-efficacy, and clinical competence. These findings demonstrated that competence and self-efficacy regarding 
specific medical and critical care nursing were significantly higher after participating in the simulation program. These findings associated with the findings of previous research.

Effective communication between student nurses and patients is essential for the skills for integrating into clinical practice to enhance student education [30]. The current study shows that communication skill of the study group improved after participation of simulation-based training. This result goes with the finding by McGaghie et al. [31], which suggests that statistical significant improvements in communication skill in clinical skill amenable like inserting a chest tube.

Table 1. Descriptive statistics for demographic variables $(\mathrm{N}=100)$.

\begin{tabular}{|c|c|c|}
\hline Variable & Number & Frequency (\%) \\
\hline \multicolumn{3}{|l|}{ Age: } \\
\hline$\bullet<20$ & 17 & $17 \%$ \\
\hline - $20-24$ & 49 & $49 \%$ \\
\hline$\bullet>24$ & 34 & $34 \%$ \\
\hline \multicolumn{3}{|l|}{ Level: } \\
\hline • level 6 & 53 & $53 \%$ \\
\hline$\bullet$ level 7 & 47 & $47 \%$ \\
\hline \multicolumn{3}{|c|}{ Previous experience with simulation: } \\
\hline - Yes & 34 & $34 \%$ \\
\hline - No & 66 & $66 \%$ \\
\hline
\end{tabular}

Table 2. Compare between pre and post-study group regarding communication skills post-simulation training $(\mathrm{N}=100)$.

\begin{tabular}{|c|c|c|c|c|}
\hline \multirow[t]{2}{*}{ Items } & \multirow{2}{*}{$\begin{array}{l}\text { Pre- } \\
\text { intervention } \\
M(S D)\end{array}$} & \multirow{2}{*}{$\begin{array}{l}\text { Post- } \\
\text { intervention } \\
M(S D)\end{array}$} & \multicolumn{2}{|c|}{ Test statistics } \\
\hline & & & t-test & $P$ value \\
\hline 1) The student has eye contact to the patient & $1.23(0.46)$ & $2.60(0.53)$ & & \\
\hline 2) The student talks face to face with the patient & $1.52(0.50)$ & $2.62(0.58)$ & & \\
\hline $\begin{array}{l}\text { 3) The student explains what he is doing to the } \\
\text { patient and why }\end{array}$ & $1.55(0.53)$ & $2.57(0.50)$ & & \\
\hline 4) The student talks by easy way to be understood & $1.63(0.61)$ & $2.63(0.52)$ & & \\
\hline 5) The student explains technical terms to the patient & $1.70(0.50)$ & $2.63(0.52)$ & & \\
\hline $\begin{array}{l}\text { 6) The student give the patients chance to ask } \\
\text { questions }\end{array}$ & $1.90(0.57)$ & $2.62(0.52)$ & -32.64 & 0.001 \\
\hline $\begin{array}{l}\text { 7) Student explains to the patient that the action } \\
\text { could be painful }\end{array}$ & $1.65(0.58)$ & $2.73(0.45)$ & & \\
\hline 8) Student politely answer the patients question & $1.53(0.62)$ & $2.58(0.53)$ & & \\
\hline $\begin{array}{l}\text { 9) Student uses word that are easy to understand } \\
\text { for the patient }\end{array}$ & $1.45(0.62)$ & $2.65(0.48)$ & & \\
\hline 10) Student executes the action correctly & $1.68(0.65)$ & $2.67(0.60)$ & & \\
\hline
\end{tabular}

$P$ value significant at the 0.05 level. 
Table 3. Compare between pre- and post-intervention group related to self-efficacy after implementing simulation program $(\mathrm{N}=100)$.

\begin{tabular}{|c|c|c|c|c|}
\hline \multirow[t]{2}{*}{ Items } & \multirow{2}{*}{$\begin{array}{l}\text { Pre- } \\
\text { intervention } \\
M(S D)\end{array}$} & $\begin{array}{l}\text { Post- } \\
\text { intervention }\end{array}$ & \multicolumn{2}{|c|}{ Test statistics } \\
\hline & & $M(S D)$ & t-test & $P$ value \\
\hline $\begin{array}{l}\text { 1) Feel confident about training that based upon } \\
\text { high-fidelity patient simulation }\end{array}$ & $1.68(0.70)$ & $3.88(0.78)$ & & \\
\hline $\begin{array}{l}\text { 2) Thanks your resourcefulness, learn know how } \\
\text { to handle unforeseen situations in a patient care } \\
\text { environment }\end{array}$ & $2.10(0.73)$ & $2.72(0.74)$ & & \\
\hline $\begin{array}{l}\text { 3) Always manage to solve complicated problems } \\
\text { when caring for patients that requires try hard } \\
\text { enough. }\end{array}$ & $2.05(0.60)$ & $3.85(1.10)$ & & \\
\hline $\begin{array}{l}\text { 4) If I find myself in trouble when caring for a } \\
\text { patient, I can usually think of a solution }\end{array}$ & $2.13(0.75)$ & $3.73(0.99)$ & & \\
\hline 5) I feel well prepared to function as a nurse & $2.45(0.59)$ & $3.85(0.90)$ & & \\
\hline $\begin{array}{l}\text { 6) I have self-confident that I could treat efficiently } \\
\text { with unexpected events and emergencies with } \\
\text { patients }\end{array}$ & $2.27(0.58)$ & $4.00(1.00)$ & & \\
\hline $\begin{array}{l}\text { 7) It is simple for me to handle my aims and } \\
\text { accomplish my goals in taking care of patients }\end{array}$ & $2.35(0.90)$ & $4.30(1.00)$ & -19.9 & 0.001 \\
\hline $\begin{array}{l}\text { 8) I feel nervous or stressed" about my ability to } \\
\text { perform well in simulation-based training }\end{array}$ & $2.25(0.57)$ & $4.00(1.00)$ & & \\
\hline $\begin{array}{l}\text { 9) I can usually handle whatever difficult situations } \\
\text { come on my way. }\end{array}$ & $2.17(0.70)$ & $4.20(0.94)$ & & \\
\hline $\begin{array}{l}\text { 10) If a co-worker of family member disagree me, I } \\
\text { can discovery the methods and ways to address the } \\
\text { situation tactfully }\end{array}$ & $2.23(0.59)$ & $4.15(0.86)$ & & \\
\hline $\begin{array}{l}\text { 11) I can solve most problems that arise in patient } \\
\text { care if I invest the necessary effort }\end{array}$ & $2.25(0.79)$ & $4.15(0.86)$ & & \\
\hline 12) I can effectively unite theory with practice & $2.25(0.84)$ & $4.17(0.91)$ & & \\
\hline $\begin{array}{l}\text { 13) We can remain calm when facing difficult } \\
\text { patient care situations because we can depend on } \\
\text { us overcome abilities. }\end{array}$ & $2.35(0.66)$ & $3.80(1.05)$ & & \\
\hline $\begin{array}{l}\text { 14) When are finding with a patient care problem, I } \\
\text { can usually find many solutions. }\end{array}$ & $2.17(0.56)$ & $3.95(0.81)$ & & \\
\hline
\end{tabular}

P value significant at the 0.05 level.

Table 4. Comparison between pre and post-intervention group regarding clinical competence after simulation-based training $(\mathrm{N}=100)$.

\begin{tabular}{|c|c|c|c|c|}
\hline \multirow[t]{2}{*}{ Items } & \multirow{2}{*}{$\begin{array}{l}\text { Pre- } \\
\text { intervention } \\
\text { M (SD) }\end{array}$} & \multirow{2}{*}{$\begin{array}{l}\text { Post- } \\
\text { intervention } \\
M(S D)\end{array}$} & \multicolumn{2}{|c|}{ Test statistics } \\
\hline & & & t-test & $P$ value \\
\hline $\begin{array}{l}\text { 1) In the clinical skills center (CSC), can } \\
\text { repeated procedure tasks until can } \\
\text { confident which I am implementing } \\
\text { them correctly }\end{array}$ & $3.32(1.11)$ & $3.78(0.76)$ & & \\
\hline $\begin{array}{l}\text { 2) In the clinical skills center, learning a } \\
\text { long and complex procedure in small parts. }\end{array}$ & $3.08(1.12)$ & $3.98(0.75)$ & & \\
\hline
\end{tabular}




\section{Continued}

3) In the clinical skills center, we can get adequate help when we are struggling

$3.00(0.99) \quad 4.02(0.83)$ with something

4) Practicing in the clinical skills center must artificial to be beneficial

5) It's good to be able to produce mistakes and know that nobody will get damage.

6) Things we do in CSC, assist me to understand some of the theory I having taught.

7) Time spent in CSC lead to continuous improvement of clinical skills

8) Practicing in CSC makes students more self-confident when they perform the $2.10(0.54)$ same procedure to the patients.

9) In hospital often using the skills learnt in the CSC

$2.00(0.84) \quad 3.93(0.71)$

10) Practicing in CSC improves the performance on clinical rotation

11) Practicing in the clinical skills center makes your behavior on clinical training safer for patients

12) In the clinical skills center (CSC) we find suggestions from my peers about how to improve what you do

13) We best learn when educators demonstrate the skill before I am doing it myself

14) We best learn with group of peers through we help one other

15) Assessing the skills in the CSCis a logical measure of your skills in practice.

16) Skill educated and practiced in the CSC could be better done in a clinical area (CA)

17) When we can do a skill in CSC we need training with actual patients

18) Nursing manikins are realistic for helping to develop my skills.

19) We are performing better in CSC than with actual patients

20) We are performing better with real patients than in CSC.

21) We have enjoyed when using CSC. $2.02(0.71) \quad 3.88(0.85)$

22) We have learned more in CSC or not. $2.27(0.76)$

23) Preparation sessions before start the procedure helped you enough or not. 
Table 5. Comparison between demographic characteristics and communication, selfefficacy, and competency $(\mathrm{N}=100)$.

\begin{tabular}{|c|c|c|c|}
\hline \multirow{2}{*}{ Characteristics } & Communication & Self-Efficacy & Competency \\
\hline & $M(S D)$ & $M(S D)$ & $M(S D)$ \\
\hline \multicolumn{4}{|l|}{ Gender: } \\
\hline - Male & $2.67(0.18)$ & $4.07(0.14)$ & $4.09(0.15)$ \\
\hline \multirow[t]{2}{*}{ - Female } & $2.62(0.23)$ & $3.87(0.70)$ & $3.72(0.45)$ \\
\hline & $\mathrm{t}=0.641, \mathrm{p}=0.524$ & $\mathrm{t}=0.979 . \mathrm{p}=0.332$ & $\mathrm{t}=2.768, \mathrm{p}=0.008$ \\
\hline \multicolumn{4}{|l|}{ Level: } \\
\hline - Level 6 & $2.64(0.20)$ & $3.95(0.51)$ & $3.84(0.45)$ \\
\hline \multirow[t]{2}{*}{ - Level 7} & $2.61(0.25)$ & $3.86(0.77)$ & $3.74(0.41)$ \\
\hline & $\mathrm{t}=0.597, \mathrm{p}=0.553$ & $\mathrm{t}=0.529, \mathrm{p}=0.599$ & $\mathrm{t}=0.871, \mathrm{p}=0.387$ \\
\hline \multicolumn{4}{|c|}{ Experience with simulation: } \\
\hline - Yes & $2.58(0.25)$ & $3.85(0.76)$ & $3.74(0.40)$ \\
\hline \multirow[t]{2}{*}{ - No } & $2.66(0.19)$ & $3.95(0.54)$ & $3.83(0.46)$ \\
\hline & $\mathrm{t}=-1.473, \mathrm{p}=0.146$ & $\mathrm{t}=-0.589, \mathrm{p}=0.558$ & $\mathrm{t}=-0.804, \mathrm{p}=0.425$ \\
\hline
\end{tabular}

P value significant at the 0.05 level.

Young and colleagues [32] show that improvement of the communication skills over time in clinical practice after course participation. Similarity, Thidemann and Söderhamn [33] exhibit that high fidelity simulation (HFS) could be progressed and improved communication skills (CS) in students of health training. Foronda et al. [34] also show that student having good communication skill help them to make efficient assessment the patient prior to call the doctor. However, a recent study showed statistically significant improvement for communication scores perceived by observers report for medical students group [35]. The Jahan et al. [36] review found that communication skills are core competencies necessary for better patient care and it is important for nursing educators in clinical setting.

The result of the current study shows that high means scores of self-efficacy scale post-simulation than pre-simulation. This finding is congruent with pretest and posttest intervention conducted on 98 students. The author found significantly improvement of students' self-efficacy in the skills performance and learning after participation simulation program as well a positive effect on students' achievement outcome [37]. Shinnick et al. [37] also conducted a quiz experimental study on 161 students in three nursing schools concluded that there was increased in SE scores for the experimental group than control. Similarly, Paravattil [38] suggests that high self-efficacy and learning outcomes in nursing students of medical-surgical graduate nurses' after simulation-based teaching program.

The result of the present study indicated that statistically significant improved of clinical competence scale from before to after simulation-based training. This result was consistent with Dahye and Hyun-Jung [39] conducted randomized 
controlled trial (RCT), pre-post intervention on 35 nursing students underwent training in the medical-surgical nursing education. They found that statistically significant improvements of the knowledge, confidence, critical thinking, and clinical competence to advanced cardiovascular life support. Williams and Song [40] also conducted a cross-sectional study among 33 nursing students, the authors showed simulated patients (SPs) improved students' clinical competency. Other studies Kim \& Jang [41] provide that competence improved after highfidelity simulation education. Similarly, Danielle [42] shows that improved in clinical competence of students in a medical-surgical nursing course from midterm to final. These, attributed that students with a high-level communication skills, self-efficacy (SE) and clinical competence have a positive impact on patients outcome. Our results are in contrast to Blum et al. [43] carried out study on 53 bachelor sciences nursing students shows that no significant difference in self-confidence and clinical competence between the both groups (one used HFS and another used the traditional approach.

Our study revealed that there was significant relation between gender and clinical competency. These findings supported by Sri Linuwih et al. [44], which showed that the clinical competence of female students was better than the male students regarding the aspects of history taking and professionalism. Similarly, Soheilipour and Farajzadeh [44] found that no significantly different in nurses' clinical competence as general and gender overtime $(\mathrm{P}>0.05)$.

\section{Limitations of the Study}

- The current research was limited by small sample size, so these findings cannot be generalized.

- The participants were not randomly selected and not control study.

\section{Conclusion and Recommendations}

The findings of this research showed that students simulation-based program improves the mean scores of communication skill, self-efficacy and clinical competence after participation of simulation-based training. There is significantly correlation between gender and clinical competence. Future research, integrate the multiple-patient simulation as a teaching-learning strategy in the nursing curriculum. Also, replication of the study with a larger sample of students from different universities during the bachelor science of nursing program may have more generalized effect.

\section{Conflicts of Interest}

The authors declare no conflicts of interest regarding the publication of this paper.

\section{References}

[1] Cordeau, M.A. (2012) Linking the Transition. A Substantive Theory of High-Stakes 
Clinical Simulation. Advances in Nursing Science, 35, E90-E102. https://doi.org/10.1097/ANS.0b013e318262614f

[2] Jeffries, P.R. (2012) Simulation in Nursing Education: From Conceptualization to Evaluation. 2nd Edition, National League for Nursing, New York.

[3] Como, J.M., Kress, M. and Lewental, M. (2009) High Fidelity Simulation Use in an Undergraduate Nursing Program. Proceedings of the ASCUE 2009, Myrtle Beach, SC, 14-18 June 2009.

[4] Pulido-Martos, M., Augusto-Landa, J.M. and Lopez-Zafra, E. (2012) Sources of Stress in Nursing Students: A Systematic Review of Quantitative Studies. International Nursing Review, 59, 15-25. https://doi.org/10.1111/j.1466-7657.2011.00939.x

[5] Oermann, M.H. and Gaberson, K.B. (2014) Evaluation and Testing in Nursing Education. 4th Edition, Springer, New York.

[6] Bradshaw, M.J. and Lowenstein, A.J. (2014) Innovative Teaching Strategies in Nursing and Related Health Professions. 6th Edition, Jones and Bartlett, Burlington, MA.

[7] O'Connor, A.B. (2015) Clinical Instruction and Evaluation. 3rd Edition, Jones and Bartlett, Burlington, MA.

[8] American Nurses Association (2017) Call for Action: Nurses Lead and Transform Palliative Care. Silver Spring, Montgomery, MD.

https://www.nursingworld.org/practice-policy/health-policy/pro-issues-panel/pallia tive-and-hospice-nursing-panel/

[9] Tosterud, R., Hedelin, B. and Hall-Lord, M.L. (2013) Nursing Students' Perceptions of High- and Low-Fidelity Simulation Used as Learning Methods. Nurse Education in Practice, 13, 262-270.

[10] Aari, R.L., Tarja, S. and Helena LK. (2008) Competence in Intensive and Critical Care Nursing: A Literature Review. Intensive and Critical Care Nursing, 24, 78-89. https://doi.org/10.1016/j.iccn.2007.11.006

[11] Gantt, L.T. (2010) Using the Clark Simulation Evaluation Rubric with Associate Degree and Baccalaureate Nursing Students. Nursing Education Perspectives, 31, 101-105.

[12] Kim, J., Park, J.-H. and Shin, S. (2016) Effectiveness of Simulation-Based Nursing Education Depending on Fidelity: A Meta-Analysis. BMC Medical Education, 16, 152. https://doi.org/10.1186/s12909-016-0672-7

[13] Bandura, A. (1997) Self-Efficacy: The Exercise of Control. W.H. Freeman, New York.

[14] Richardson, M., Abraham, C. and Bond, R. (2012) Psychological Correlates of University Students' Academic Performance: A Systematic Review and Meta-Analysis. Psychological Bulletin, 138, 353-387. https://doi.org/10.1037/a0026838

[15] Van Dinther, M., Dochy, F. and Segers, R.M. (2011) Factors Affecting Students' Self-Efficacy in Higher Education. Educational Research Review, 6, 95-108. https://doi.org/10.1016/j.edurev.2010.10.003

[16] Valizadeh, L., Amini, A., Fathi-Azar, E., Ghiasvandian, S. and Akbarzadeh, B. (2013) The Effect of Simulation Teaching on Baccalaureate Nursing Students' Self-Confidence Related to Peripheral Venous Catheterization in Children: A Randomized Trial. Journal of Caring Sciences, 2, 157-164.

[17] Lin, H.H. (2015) Effectiveness of Simulation-Based Learning on Student Nurses' Self-Efficacy and Performance While Learning Fundamental Nursing Skills. Technology and Health Care, 24, S369-S375. https://doi.org/10.3233/THC-151094 
[18] Roh, Y. (2014) Effects of High-Fidelity Patient Simulation on Nursing Students' Resuscitation-Specific Self-Efficacy. CIN: Computers, Informatics, Nursing, 32, 84-89. https://doi.org/10.1097/CIN.0000000000000034

[19] Khalaila, R. (2013) Simulation in Nursing Education: An Evaluation of Students' Outcomes at Their First Clinical Practice Combined with Simulations. Nurse Education Today, 34, 252-258. https://doi.org/10.1016/j.nedt.2013.08.015

[20] Benner, P. (1982) Issues in Competency-Based Testing. Nursing Outlook, 30, 303-309.

[21] Kane, M.T. (1992) The Assessment of Professional Competence. Evaluation \& the Health Professions, 15, 163-182. https://doi.org/10.1177/016327879201500203

[22] Herrman, J.W. (2015) Creative Teaching Strategies for the Nurse Educator. FA Davis Co., Philadelphia, PA.

[23] Swenty, C.F. and Eggleston, B.M. (2011) The Evaluation of Simulation in Baccalaureate Nursing Program. Clinical Simulation in Nursing, 7, e181-e187. https://doi.org/10.1016/j.ecns.2010.02.006

[24] Rosen, K.R. (2008) The History of Medical Simulation. Journal of Critical Care, 23, 157-166. https://doi.org/10.1016/j.jcrc.2007.12.004

[25] Kelly, S.H. (2014) Evaluation Methods Used In Simulation: A Survey of Faculty and Student Perceptions in an Undergraduate Nursing Program. University of Pittsburgh, Pittsburgh, PA.

[26] Luszczynska, A., Diehl, M., Gutiérrez-Doña, B., Kuusinen, P. and Schwarzer, R. (2004) Measuring One Component of Dispositional Self-Regulation: Attention Control in Goal Pursuit. Personality and Individual Differences, 37, 555-566. https://doi.org/10.1016/j.paid.2003.09.026

[27] Yoo, M.S. (2001) Development of Standardized Patient Managed Instruction for a Fundamental of Nursing Course. Unpublished Doctoral Dissertation, Yonsei University, Seoul.

[28] Yang, J. and Park, M. (2004) The Relationship of Clinical Competence and Self-Directed Learning in Nursing Students. Journal of Korean Academic Society of Nursing Education, 10, 271-277.

[29] Freeth, D. and Fry, H. (2005) Nursing Students' and Tutors' Perceptions of Learning and Teaching in a Clinical Skills Centre. Nurse Education Today, 25, 272-282. https://doi.org/10.1016/j.nedt.2005.01.007

[30] Schiavenato, M. (2009) Reevaluating Simulation in Nursing Education: Beyond the Human Patient Simulator. Journal of Nursing Education, 48, 388-394. https://doi.org/10.3928/01484834-20090615-06

[31] McGaghie, W.C., Issenberg, S.B., Petrusa, E.R. and Scalese, R.J. (2014) A Critical Review of Simulation-Based Medical Education Research: 2003-2009. Medical Education, 44, 50-63. https://doi.org/10.1111/j.1365-2923.2009.03547.x

[32] Young, K., Eun, K. and Sook, L. (2012) Effects of Simulation-Based Education on Communication Skill and Clinical Competence in Maternity Nursing Practicum. Korean Society of Women Health Nursing, 18, 312-320. https://doi.org/10.4069/kjwhn.2012.18.4.312

[33] Thidemann, I.J. and Söderhamn, O. (2013) High-Fidelity Simulation among Bachelor Students in Simulation Groups and Use of Different Roles. Nurse Education Today, 33, 1599-1604. https://doi.org/10.1016/j.nedt.2012.12.004

[34] Foronda, L.C., Gattamorta, K., Snowden, K. and Bauman, B.E. (2013) Use of Virtual Clinical Simulation to Improve Communication Skills of Baccalaureate Nursing 
Students: A Pilot Study. Nurse Education Today, 34, e53-e57. https://doi.org/10.1016/j.nedt.2013.10.007

[35] Ammentorp, J., Thomsen, J.L., Jarbøl, D.E., Holst, R., Øvrehus, A.L. and Kofoed, P.E. (2013) Comparison of the Medical Students' Perceived Self-Efficacy and the Evaluation of the Observers and Patients. BMC Medical Education, 13, 49. https://doi.org/10.1186/1472-6920-13-49

[36] Jahan, F., Moazzam, M., Norrish, M. and Naeem, M.S. (2014) Comparison of the Medical Students' Self-Assessment and Simulated Patients Evaluation of Students' Communication Skills in Family Medicine Objective Structured Clinical Examination (OSCE). Middle East Journal of Family Medicine, 12, 30-37.

[37] Shinnick, M.A. and Woo, M.A. (2014) Does Nursing Student Self-Efficacy Correlate with Knowledge When Using Human Patient Simulation? Clinical Simulation in Nursing, 10, e71-e79. https://doi.org/10.1016/j.ecns.2013.07.006

[38] Paravattil, B. (2012) Preceptors' Self-Assessment of their Ability to Perform the Learning Objectives of an Experiential Program. American Journal of Pharmaceutical Education, 76, 169. https://doi.org/10.5688/ajpe769169

[39] Dahye, P. and Kim, H.-J. (2018) Effects of a Simulation-Based Training on Nursing Students' Knowledge, Confidence, Clinical Competence and Clinical Competence to Advanced Cardiovascular Life Support. Journal of Convergence for Information Technology, 9, 61-67.

[40] Kim, Y.H. and Jang, K.S. (2011) Effect of a Simulation-Based Education on Cardio-Pulmonary Emergency Care Knowledge, Clinical Performance Ability and Problem Solving Process in New Nurses. Journal of Korean Academy of Nursing, 41, 245-255. https://doi.org/10.4040/jkan.2011.41.2.245

[41] Danielle, R. (2013) High-Fidelity Nursing Simulation: Impact on Student Self-Confidence and Clinical Competence. http://liblink.bsu.edu/catkey/1718489

[42] Blum, A.C., Borglund, S. and Parcells, D. (2010) High-Fidelity Nursing Simulation: Impact on Student Self-Confidence and Clinical Competence. International Journal of Nursing Education Scholarship, 7, 18. https://doi.org/10.2202/1548-923X.2035

[43] Sri Linuwih, S.W.M., Aria, K., Iwan, D., Ova, E. and Yayi, S.P. (2018) The Correlation Between Gender and Achievement of Clinical Competence: A Review on Psychological Profile in Medical Students. Advanced Science Letters, 24, 6910-6913. https://doi.org/10.1166/asl.2018.12882

[44] Soheilipour, K. and Farajzadeh, Z. (2016) Evaluating the Clinical Competence of Junior Nursing Staff Based on Self-Assessment in Valiasr Hospital of Birjand in 2015-16. Modern Care Journal, 13, e10089. https://doi.org/10.5812/modernc.10089 